\title{
J. B. Watson and J. J. B. Morgan: The original drive theory of motivation
}

\author{
N. R. REMLEY \\ Texas Christian University, Fort Worth, Texas 76129
}

\begin{abstract}
John B. Watson and J. J. B. Morgan published an article in 1917 in which they introduced the term "drive" as a motivational construct. The article was published 8 months before R. S. Woodworth published his book, Dynamic Psychology, in which he used the term "drive." Most historians of psychology have given Woodworth credit for introducing the term into American psychology. Not only did Watson and Morgan introduce the term before Woodworth, but also they offered a much more systematic theory of motivation, one in which "drive" was a central concept.
\end{abstract}

The singularly most important concept in motivational theory for the last 50 years has probably been the term "drive." Although the German word "trieb" was used by some early European psychologists, it was not used with the same meaning that was assigned to the term "drive" by the early American psychologists. "Trieb" was used to imply the force of specific acts, such as food-seeking drive (nahrungstrieb) and activity drive (tatigkeitstrieb).

Most writers of textbooks on motivation usually credit Woodworth (1918) with introducing the concept into American psychological theory when he used it in his book, Dynamic Psychology. Justification for this assertion was provided by Woodworth in a letter he sent to Young, which Young quoted in Motivation of Behavior:

I believe you are right in supposing that the current use of "drive" in animal psychology and other psychology springs from my use of the word in Dynamic Psychology, 1918. I am sure I did not derive the word from any previous psychologist. I got it from mechanics. A machine has a mechanism such that if it is put in motion it operates in a certain way; but it must be driven in order to move. The "drive" of a machine is the supply of energy that puts it in motion (Young, 1936, p. 71).

Although Woodworth (1918) may not have derived the term from any "previous psychologist," he was not the first American psychologist to use it in a systematic, theoretic way. This honor should go to Watson and Morgan, who published a paper in the April 1917 issue of the American Journal of Psychology entitled "Emotional Reactions and Psychological Experimentation." In this paper Watson and Morgan attempted to provide the logical and experimental bases for specifying the "group of emotional reactions as belonging to the original and fundamental nature of man: fear, rage, and love (using love in approximately the same sense that Freud uses sex)"
(Watson \& Morgan, 1917, p. 165). After providing some experimental data for the above statement, Watson and Morgan cited some physiological research which they believed strengthened their hypothesis that fear, rage, and love were innate emotional reactions. In providing this physiological base for their position, they introduced the term "drive" to explain how these emotional reactions affected behavior. They stated:

It is from Cannon's work that we get our
best experimental evidence that under the
influence of secretions called out from the
ductless glands by major emotions the organ-
ism's physiological state is so changed that
it can do things (and endure things) which
it could not do when such secretions are
absent. This is our real evidence for the
assumption that the emotions furnish the
"drive" for many forms of activity (Watson
\& Morgan, 1917, p. 170).

It is quite clear that Watson and Morgan meant the term "drive" to have the activating and energizing functions that contemporary motivational theory subsumes with the use of the term. Furthermore, Watson and Morgan used the term to mean a generalized activating process rather than a specific force for a specific behavior, as the Europeans had used the term "trieb."

Watson and Morgan spoke of "drive" as energizing behaviors that were not associated with the original source of the drive (i.e., the emotions). For example, they stated:

We here utilize in an experimental way the emotional "drive" to bring about an increase in the strength and endurance of a nonemotional act (viz., in the grasping reflex). This leads us to our central topic. We have tried to show as best we can in the lack of more exact experimental evidence (1) that by the method of conditioned reflexes, 
emotional reactions can be called out by situations (stimuli) which do not at first call them out; and (2) that emotions, by virtue of the secretions which are present, furnish a "drive" (possibility of reaction or continuance of the reaction) which is lacking in ordinary instinctive and habitual actions. These two assumptions, if they are true, should bring the subject of emotions directly into the focus of experimentation (Watson \& Morgan, 1917, p. 171).

Clearly, this is the generalized "drive" concept spoken of by later motivational theorists such as Woodworth (1918). The above quoted statement also indicates that Watson and Morgan (1917) anticipated the development of the concept of acquired drive through the process of classical conditioning that Miller (1951) demonstrated many years later.

Watson and Morgan (1917) also suggested that the performance of individuals in school and industry might be altered by manipulation of drive by manipulating irrelevant emotions. In addressing the question of how a businessman might get better performance from his employees, they stated:

The solution would appear to lie in getting the act, in which improvement has ceased, hitched up in some way with an emotional state, for in this way an added "drive" may appear and a new level of adjustment be reached. Whether connection should be made through rage, fear, or love is an experimental problem (Watson \& Morgan, 1917, p. 173).

In a footnote on the same page, they added:

It is interesting to note here too how early this conception of the "added drive" throws light upon the fact that under the influence of high emotional stimulation outcasts from society have been known to come back and to reestablish a stable system of habits. Oftentimes the emotional period does not last long enough for stable habits to be formed and the "convert" backslides. Marriages to save the man when they have resulted in reformation may owe their happy culmination to this factor. Possibly a more judicious and less prodigal use of sex in the early stages of marriage (thus maintaining the high emotional state for a longer period of time) would bring about a much larger number of reformations (Watson \& Morgan, 1917, p. 173).

Another interesting feature of the Watson and Morgan concept of drive is in the reductive nature of the term as they used it. They not only defined the term by its behavioral activating effects, but also equated the effects of drive to the "calling out of the secretions from the ductless glands" (Watson \& Morgan, 1917, p. 170). It should be noted that by associating drive mechanistically with activation of the endocrine system during emotional arousal, Watson and Morgan provided a deductive testability to their theory that was somewhat uncommon in that day. That is, they provided for the possibility of testing their theory by producing changes in drive independent of the way in which it was originally defined (i.e., the emotions). Their theory predicted that any experimental manipulation that "called out the secretions from the ductless glands" would result in an increase in drive. In defining drive both as changes in behavioral activation and as changes in physiological activity, their concept of drive does not have the hint of circularity that was often associated with the term as used by later theorists. Had the Watson and Morgan (1917) theory of drive been recognized and tested by other psychologists, it might have reduced the possibility of drive developing many of the metaphorical characteristics that have since become associated with the concept.

It should be noted that every time Watson and Morgan used the term "drive" in their paper, the term was enclosed in quotation marks. This suggests that they were attempting to draw attention to a new and different way of using the term. If they were simply using an already established theoretic term, their use of the quotation marks would have been confusing and would have led to gross misunderstanding. Certainly, their use of "drive" was very different from that of any other motivational term used by psychologists at that time. A wide variety of terms was used to imply motivational processes, but none approached the meaning that drive possessed as used by Watson and Morgan (1917). The most commonly used terms to describe motivational processes were "will" (James, 1915), "instinct" (McDougall, 1912), "desire" (Dunlap, 1912), and "consciousness" (Titchener, 1924). None of these terms was used in any way similar to the use of drive by Watson and Morgan. The fact that "drive" does not appear in any of the above mentioned texts lends support to the inference that Watson and Morgan were attempting to describe a new and previously unknown motivational process and that the use of quotation marks was an attempt to specify the uniqueness of this term as they were using it.

Although Watson and Morgan (1917) did not write their paper in a form that gave the appearance of proposing a formal model or theory of motivation, it is obvious that they intended to introduce a new concept in an attempt to explain behavior. The following represents an extraction of the assumptions and postulations Watson and Morgan made about drive.

(1) The original sources of drive are the three innate emotions: rage, fear, and love (sex).

(2) Drive is a generalized motivation process. 
Although drive can be stimulated by any one of the three innate emotions, all behavior is motivated by the same drive.

(3) The emotions are the original sources of drive; however, through the process of classical conditioning, drive can become attached to other, nonemotional behaviors. This is the basis for what we today call "acquired drive."

(4) The level of performance is a function of drive and not of habit. If the motivational level is altered through "added drive," there will be an increase in the level of performance.

(5) The endocrine system (ductless glands) is the physiological mechanism of drive. The hormones secreted by the endocrine glands were thought to provide the basis for the drive of all behaviors.

It is not clear why Watson and Morgan have not been recognized as the founders of modern drive theory in psychology. It is possible that no one was really interested in the history of this concept until Young apparently asked Woodworth about the origin of the term. Woodworth's self-credited claim for origination of the concept was apparently accepted without challenge. It is possible that Woodworth was not aware of the paper by Watson and Morgan when he was preparing the manuscript for his Dynamic Psychology, even though the Watson and Morgan paper was published 8 months before Woodworth's publication. Perhaps Watson and Morgan and Woodworth independently developed the concept of drive as a major mechanism of motivation, and, therefore, 18 years later Woodworth felt justified in claiming credit for being the first theorist to introduce the drive concept into motivational theory.

A comparison of the two ideas about drive leads to the conclusion that Watson and Morgan's (1917) concept was rooted in a better theoretic framework. Their concept of drive predated the direction of future research in motivation. In any respect, their article provides ample documentation that the honor of primacy for use of the term "drive" as a theoretic mechanism of motivation must go to John B. Watson and J. J. B. Morgan rather than to R. S. Woodworth.

\section{REFERENCES}

DunlaP, K. A system of psychology. New York: Scribner, 1912. James, W. Psychology. New York: Holt, 1915.

McDougall, W. Psychology: The study of behavior. New York: Holt, 1912.

Mille R, N. E. Learnable drives and rewards. In S. S. Stevens (Ed.), Handbook of experimental psychology. New York: Wiley, 1951.

Titchener, E. B. A textbook of psychology. New York: Macmillan, 1924.

Watson, J. B., \& Morgan, J. J. B. Emotional reactions and psychological experimentation. American Journal of Psychology, 1917, 28, 163-174.

Woodworth, R. S. Dynamic psychology. New York: Columbia University Press, 1918.

Young, P. T. Motivation of behavior. New York: Wiley, 1936.

(Received for publication July 25,1980 .) 